\title{
Comportamento de genótipos de arroz de terras altas na Zona da Mata de Pernambuco
}

\author{
Vaubam A. C. da Silva ${ }^{1}$, Edson F. da Silva ${ }^{2} \&$ Jose N. Tabosa ${ }^{3}$
}

\begin{abstract}
RESUMO
Avaliou-se, neste estudo, o comportamento de 12 genótipos de arroz de terras altas na Zona da Mata de Pernambuco quanto a caracteres de importância agronômica. Utilizou-se 0 delineamento de blocos ao acaso, com 4 repetições, parcelas constituídas de 5 linhas de $4 \mathrm{~m}$ e espaçamento de $0,50 \mathrm{~m}$. 0 s experimentos foram conduzidos no ano agrícola de 2006, entre os meses de abril e agosto, nos municípios de Pal mares e Vitória de Santo Antão. Dentre os caracteres avaliados verificaram-se diferenças significativas entre os genótipos para os caracteres: altura de planta, acamamento, ciclo de florescimento e de maturação, perfilhamento médio, comprimento de panículas, peso de mil grãos e rendimento de grãos inteiros. A interação genótipo $\mathrm{x}$ ambiente foi significativa para os caracteres altura de planta, ciclo de florescimento e percentual de espiguetas estéreis. $0 \mathrm{~s}$ genótipos Bonança, BRA 1506, CNAs 9045 e BRSMG curinga, apresentaram os melhores comportamentos para os caracteres: altura da planta, acamamento, ciclo de florescimento e de maturação, além de bom perfilhamento e médio rendimento e, portanto, são os mais promissores a serem recomendados para o plantio na referida região, especificamente no período entre os meses de abril a julho.
\end{abstract}

Palavras-chave: 0 ryza sativa L., produtividade, interação genótipo ambiente

\section{Performance of upland rice genotypes in 'Zona da Mata' of Pernambuco State}

\begin{abstract}
Twelve upland rice genotypes were evaluated in the 'Zona da Mata' of Pernambuco State regarding characteristics of agronomical importance. The experimental design was randomized block with four replications and plots composed of 5 rows of 4 $\mathrm{m}$ length and $0.5 \mathrm{~m}$ spacing. The experiments were carried out from A pril to August during the agricultural year 2006 at the Palmares and Vitoria de Santo Antão municipalities. Amongst the evaluated characteristics there were significant differences among genotypes for plant height, lodging, flowering and maturation cycle, number of tillers per plant, length of panicle, 1000-grain weight and grain yield. Genotype versus environment interaction was significant for the characteristics of plant height, flowering, cycle and percentage of spikelet sterility. The genotypes Bonança, BRA 1506, CNAs 9045 and BRSM G curinga showed better performance on plant height, lodging, flowering and maturation cycles besides good tillering per plant and average yield. Therefore, these genotypes bring a good perspective for cultivation in the region during the period of A pril to July.
\end{abstract}

Key words: Oryza sativa L., productivity, genotype versus environment interaction 


\section{INTRODUÇÃO}

O arroz (Oryza sativa L.) é uma das culturas de maior importância social e econômica no mundo, por se tratar de um dos principais produtos da cesta básica e fonte primordial de calorias em grãos, fornecendo $21 \%$ das calorias e $14 \%$ das proteínas necessárias ao ser humano (Ferreira et al., 2005). Segundo Muralidharan et al. (2002) este cereal é cultivado anualmente em cerca de 148 milhões de hectares no mundo. O Brasil é o nono produtor mundial, com produção de 13.191.885 t em 2005 (IBGE, 2006).

A orizicultura brasileira é conduzida sob quatro sistemas básicos de cultivo, em dois ecossistemas: o de várzeas e o de terras altas. No ecossistema de várzea o cultivo deste cereal pode ser conduzido em várzea sistematizada, com controle da lâmina de água predominante no Estado do Rio Grande do Sul e em várzea úmida não sistematizada, irrigadas pela água da chuva ou pela elevação dos lençóis freáticos (Guimarães \& Sant'Ana, 1999); já no ecossistema de terras altas o arroz é cultivado em terras firmes nas quais os índices pluviométricos, as enchentes dos rios ou o afloramento natural dos lençóis freáticos, são as fontes de água disponíveis para o desenvolvimento das plantas. Este ecossistema pode ser também realizado com irrigação suplementar por aspersão que proporciona alta produtividade, mas depende de maiores investimentos para implantá-lo (Rangel, 1995).

Villar \& Ferreira (2005) citam que, no Brasil, no período de 1996 a 2000 o sistema de cultivo de arroz irrigado representou $34,5 \%$ da área plantada, respondendo por $61 \%$ da produção, enquanto o sistema de terras altas representou $65,5 \%$ da área plantada e $39 \%$ da produção, sendo que, segundo Crusciol et al., (2005) a quase totalidade do arroz produzido no ecossistema de terras altas é cultivada no Cerrado brasileiro. O cultivo do arroz no Estado de Pernambuco é feito apenas nas margens do Rio São Francisco, sob o sistema de cultivo irrigado. A produção nesta região foi, em 2005, de 47.082 t em 9.203 ha, com produtividade em torno de $5.100 \mathrm{~kg} \mathrm{ha-}{ }^{1}$, tendo-se destacado como maior produtor o município de Cabrobó, com 30.000 t, seguido de Belém de São Francisco, Santa Maria da Boa Vista e Orocó, com 7.417, 3.480 e 2.400 t, respectivamente (IBGE, 2006).

Embora a Zona da Mata de Pernambuco apresente condições edafoclimáticas perfeitamente adequadas para o cultivo de arroz em terras altas, ainda não havia sido testado material para este ecossistema. A avaliação de genótipos para tais situações, tem sido desenvolvida para outras regiões do Brasil, a exemplo de resultados obtidos por Utimi et al. (2001) no Estado de Rondônia, Soares et al. (2003b) em Minas Gerais e Moura Neto et al. (2002) no Estado de Goiás.

Para que haja expansão da área de cultivo e ocorra aumento da produtividade, é de fundamental importância a avaliação de genótipos promissores em regiões que tenham potencialidade, considerando-se a interação genótipo x ambientes e os parâmetros genéticos que subsidiam a identificação de genótipos mais adaptados.
O entendimento da interação genótipo $\mathrm{x}$ ambiente permite avaliar a influência da interação em relação à variância do caráter em análise conjunta de grupos de experimentos, em diferentes locais e, dependendo do objetivo específico do programa de melhoramento, possibilita maiores ganhos com a seleção (Cruz et al., 2004; Vencovsky \& Barriga, 1992); além disso, conhecimentos quanto aos coeficientes de herdabilidade média dos caracteres são parâmetros que também auxiliam no processo de seleção de genótipos superiores nos programas de melhoramento genético (Falconer, 1987; Cruz, 2005).

Neste contexto, a avaliação de genótipos de arroz em ensaios de competição, explorando o entendimento da interação genótipo x ambiente e de parâmetros genéticos, propicia a identificação de genótipos superiores. Propôs-se, com o presente trabalho, avaliar o comportamento agronômico de 12 genótipos de arroz de terras altas na Zona da Mata de Pernambuco.

\section{MATERIAL E MÉTODOS}

Os experimentos foram conduzidos no ano agrícola de 2006, em dois locais da Zona da Mata de Pernambuco: Vitória de Santo Antão, Zona da Mata Centro e Palmares, Zona da Mata Sul. Em Vitória de Santo Antão, o experimento foi conduzido na Escola Agrotécnica, localizada a $08^{\circ} 07^{\prime} 11^{\prime \prime}$ S e $30^{\circ} 17^{\prime}$ '58" W e, em Palmares, na Escola Agrícola, localizada a $08^{\circ} 41^{\prime} 00^{\prime \prime}$ $\mathrm{S}$ e $35^{\circ} 35^{\prime} 30^{\prime}$ 'W.

A condução dos experimentos ocorreu entre os meses de abril a julho, período que corresponde ao ano agrícola de culturas anuais na região; os tratos culturais e fitossanitários foram realizados conforme as recomendações técnicas para o cultivo do arroz de terras altas (Breseghello \& Stone, 1998).

Avaliaram-se 12 genótipos, dos quais dez oriundos do Centro Nacional de Pesquisa de Arroz e Feijão CNPAF Embrapa, um do Centro de Pesquisa Meio-Norte CPAMN Embrapa e um do Instituto Agronômico de Campinas (IAC) (Tabela 1). Para a escolha desses materiais consideraram-se o ciclo (precoce e semiprecoce) e as características comerciais, tais como classe de grão longo fino, aparência e qualidade de cocção.

Visando à avaliação dos caracteres em cada experimento, os genótipos foram dispostos de acordo com o delineamento experimental de blocos ao acaso com quatro blocos; as parcelas se constituíram de 5 linhas de $4 \mathrm{~m}$ de comprimento, espaçadas $0,50 \mathrm{~m}$, totalizando $10,0 \mathrm{~m}^{2}$ de área total, utilizando-se a densidade de 75 sementes por metro linear; todas as avaliações foram feitas nas 3 linhas centrais de cada parcela, totalizando $6,0 \mathrm{~m}^{2}$ de área útil.

Realizou-se, antes da semeadura, adubação química, com $150 \mathrm{~kg} \mathrm{há}{ }^{-1}$ da fórmula 4-14-8 e, quarenta e cinco dias após a emergência das plântulas, a adubação de cobertura com 30 $\mathrm{kg}$ de nitrogênio por hectare.

Os caracteres avaliados foram: altura da planta (AP), acamamento de planta (ACP), ciclo de florescimento (CF), ciclo de maturação (CM), perfilhamento médio (PM), com- 
Tabela 1. Relação dos genótipos avaliados na Zona da Mata de Pernambuco, instituição de origem e cruzamentos que as originaram

\begin{tabular}{|c|c|c|}
\hline Genótipos & $\begin{array}{l}\text { Instituição } \\
\text { de origem }\end{array}$ & Genealogias \\
\hline IAC 47 & IAC & IAC 1246 / IAC 1391 \\
\hline Bonança & CNPAF & $\begin{array}{l}\text { CT7244-9-2-1-52-1 / CT7232-5-3-7-2-1P // CT6196-33- } \\
\text { 11-1-3-AP }\end{array}$ \\
\hline $\begin{array}{l}\text { Rio } \\
\text { Parnaíba }\end{array}$ & CNPAF & IAC 47/ $63-83$ \\
\hline Maravilha & CNPAF & TOX 1010-49-1 / IRAT 121//Colombia 1 / M312A \\
\hline Caiapó & CNPAF & IRAT 13 / Beira campo // CNAx 104-B 18- Pv-28 / Perola \\
\hline BRA 1506 & CNPAF & CNA8077 / L141 // CNA 8198 / Lemont \\
\hline BRA 1600 & CNPAF & Kay Bonnet / Aimoré \\
\hline CNAs 9045 & CNPAF & $\begin{array}{l}\text { CNA } 7914 \text { / CNAx 3031-1-13-B-1-1 // CNA } 7455 \text { / } \\
\text { Colombia } 1\end{array}$ \\
\hline $\begin{array}{l}\text { CNA } 9025 \\
\text { (sertanejo) }\end{array}$ & CNPAF & Carajás / IAC 1150 // 150144 / CNAx 4036-5-1-1 \\
\hline $\begin{array}{l}\text { BRSMG } \\
\text { (curinga) }\end{array}$ & CNPAF & $\begin{array}{l}\text { CT9978 - 1221P4 / CT 10037-564M1P1 // } 569911 \text { - } \\
\text { 3P111P / CT9356 }\end{array}$ \\
\hline $\begin{array}{c}\text { BRS } \\
\text { (primavera) }\end{array}$ & CNPAF & IRAT 10 / LS 85 - 158 \\
\hline PB 5 & CPAMN & Seleção em variedades locais \\
\hline
\end{tabular}

IAC - Instituto Agronômico de Campinas, CNPAF - Centro Nacional de Pesquisa de Arroz e Feijão e CPAMN - Centro de Pesquisa Agropecuária Meio Norte

primento da panícula $(\mathrm{CP})$, peso de mil grãos (PMG), produtividade de grãos (PROD), renda (RE), rendimento de grãos (RG), percentual de espiguetas estéreis por panícula (PEEP) e percentual de espiguetas férteis por panícula (PEFP).

Para determinação da altura da planta tomaram-se dez plantas ao acaso, na área útil da parcela, nas quais se mediu o comprimento da base da planta até a extremidade da panícula, conforme Azzini et al. (1995).

A avaliação de acamamento foi realizada por meio de observações visuais no final da fase de maturação, utilizandose a seguinte escala numérica: 1 para ausência de acamamento; 3 quando mais de $50 \%$ das plantas estavam levemente acamadas; 5 quando a maioria das plantas estava moderadamente acamada; 7 quando a maioria das plantas se apresentava acamada e 9 quando todas as plantas estavam completamente acamadas.

Para determinação do ciclo de florescimento protocolouse a data do florescimento que correspondeu ao dia em que $50 \%$ das plantas apresentaram emissão da inflorescência; da mesma forma, o final do ciclo de maturação foi considerado quando $50 \%$ das panículas se apresentavam secas (cor palha), conforme Azzini et al. (1995).

Para avaliação do caracter perfilhamento médio, realizou-se a contagem das plântulas em uma amostra de um metro linear, tomada ao acaso determinando-se desta forma, o estande inicial. Por ocasião da maturação se realizou a contagem do número de perfilhos no mesmo metro linear de cada parcela. Obteve-se o perfilhamento médio pela divisão do número de perfilho no final do ciclo pelo valor obtido para o estande inicial, verificado em cada parcela.
Obteve-se o comprimento médio de panículas a partir da medição do primeiro nó até a extremidade do último grão, conforme EMBRAPA (1977), em que o valor médio obtido de 25 panículas representou as parcelas.

O peso de 1.000 grãos foi determinado por meio da avaliação de oito amostras de 100 sementes por parcela com umidade de $13 \%$. Quando o coeficiente de variação das oito amostras não ultrapassou $6 \%$, multiplicou-se o resultado médio do peso das amostras por dez, para se obter o peso de mil grãos para cada parcela, segundo as regras para análise de sementes (Ministério da Agricultura do Brasil, 1992).

A produtividade de grãos foi avaliada utilizando-se o total de grãos colhidos por parcela. As impurezas e espiguetas estéreis foram separadas por abanação, utilizandose peneira manual, enquanto a pesagem foi realizada com o emprego de balança mecânica com precisão de $0,1 \mathrm{~g}$ e capacidade para $25 \mathrm{~kg}$, quando os grãos apresentavam em torno $13 \%$ de umidade. As médias de produtividade de grãos por parcela foram transformadas para $\mathrm{kg} \mathrm{ha}^{-1}$.

Avaliou-se a porcentagem de espiguetas férteis por panícula por meio da contagem dos grãos férteis de todas as panículas colhidas para a avaliação do comprimento de panículas sendo o valor, em seguida, dividido pelo número total de panículas.

A porcentagem de espiguetas estéreis por panícula foi avaliada separado-as manualmente em dois grupos: granadas e estéreis; o número total de grãos estéreis foi dividido pelo número total das mesmas panículas utilizadas para determinação do número de espiguetas férteis.

A renda, que correspondente ao peso percentual dos grãos beneficiados e polidos, incluindo-se os grãos quebrados, foi avaliada a partir de uma amostra de 100 gramas do arroz "em casca" provenientes da produção total de cada parcela com $13 \%$ de umidade. Para beneficiar os grãos utilizou-se máquina para pequenas amostras (Máquina Suzuki - Modelo MT 87). A avaliação do rendimento de grãos foi representada pelo peso total de grãos inteiros após o beneficiamento da mesma amostra de $100 \mathrm{~g}$ em casca, sendo que a separação foi feita no trieur da mesma máquina utilizada no beneficiamento, cuja pesagem foi realizada em balança de precisão de $0,01 \mathrm{~g}$.

A partir da homogeneidade da variância das análises individuais dos dois locais, em que se observou relação adequada entre os quadrados médios (QM), as análises de variância em grupos de experimento foram realizadas para os caracteres avaliados; para isto, os efeitos do modelo em relação aos caracteres foram considerados fixos, exceto para o erro experimental; quando ocorreu significância nas fontes de variação, aplicou-se o teste de Tukey para comparação das médias em nível de 5\% de probabilidade. Para as análises estatísticas utilizou-se o programa Genes (Cruz, 1997).

O modelo estatístico utilizado para o cálculo das esperanças dos quadrados médios e para as fontes de variação foi proposto por Vencovsky \& Barriga (1992) em que $Y_{i j}=M+G$ ${ }_{i}+A_{j}+(G A)_{i j}+E_{i j}$, em que: $Y_{i j}=$ valor fenotípico do caráter $\mathrm{Y}$, do material genético i, no ambiente $\mathrm{j} ; \mathrm{M}=$ média geral pa- 
ramétrica dos dados em estudo; $\mathrm{G}$ - efeito do genótipo ou material genético $\mathrm{i} ; \mathrm{A}_{\mathrm{j}}$ - efeito do ambiente $\mathrm{j} ;(\mathrm{GA})_{\mathrm{ij}}$ - efeito da interação do genótipo $\mathrm{i}$ com o ambiente $\mathrm{j}$ e $\mathrm{Ei}_{\mathrm{j}}$ - erro médio associado à observação $\mathrm{Y}_{\mathrm{ij}}$.

A partir das esperanças dos quadrados médios, calculouse o coeficiente de variação para o erro ambiental utilizandose as seguintes expressões: $\mathrm{s}^{2}{ }_{\mathrm{ge}}=(\mathrm{QMP}-\mathrm{QME}) / \mathrm{r} \mathrm{n} ; \mathrm{s}_{\mathrm{gd}}^{2}=3$ $\mathrm{s}^{2}{ }_{\mathrm{ge}} ; \mathrm{s}_{\mathrm{fd}}{ }_{\mathrm{f}}=\mathrm{QMD} ; \mathrm{s}^{2}{ }_{\mathrm{e}}-(\mathrm{QME}-\mathrm{QMD}) / \mathrm{n} ; \mathrm{h}_{\mathrm{e}}{ }_{\mathrm{e}}=\left(\mathrm{s}^{2}{ }_{\mathrm{ge}}\right) /(\mathrm{QMP} /$ $\mathrm{r} \mathrm{n}), \mathrm{h}_{\mathrm{d}}^{2}=\left(\mathrm{s}_{\mathrm{gd}}^{2}\right) /\left(\mathrm{s}_{\mathrm{fd}}^{2}\right) ; \mathrm{CV}_{\mathrm{e}}=\left(100 . \mathrm{Vs}^{2}{ }_{\mathrm{e}}\right) / \mathrm{m} ; \mathrm{CV}_{\mathrm{ge}}=(100$. $\left.\mathrm{Vs}^{2}{ }_{\text {ge }}\right) / \mathrm{m} ; \mathrm{CV}_{\mathrm{gd}}=\left(100 . \mathrm{Vs}^{2}{ }_{\mathrm{gd}}\right) / \mathrm{m}$; índice $\mathrm{b}=\mathrm{CV}_{\mathrm{ge}} / \mathrm{CV}_{\mathrm{e}}$. Sen-

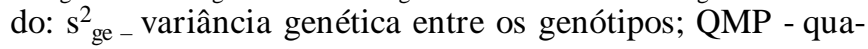
drado médio dos genótipos; QME - quadrado médio do erro entre parcelas; QMD - quadrado médio do erro dentro das

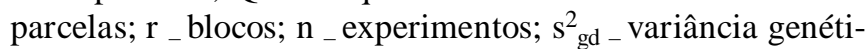
ca dentro dos genótipos; $\mathrm{s}^{2}$ fd - variância fenotípica dentro dos genótipos; $\mathrm{s}_{\mathrm{e}}^{2}$ - variância ambiental entre genótipos; $\mathrm{h}_{\mathrm{e}}^{2}$ herdabilidade entre genótipos; $\mathrm{CV}_{\mathrm{e} \text { - coeficiente de variação }}$

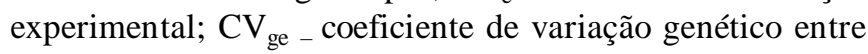
genótipos; $\mathrm{CV}_{\mathrm{gd}}$ - coeficiente de variação genético dentro dos genótipos; razão $\mathrm{CV}_{\mathrm{ge}} / \mathrm{CVe}$ (índice b); $\mathrm{m}$ - média.

\section{RESULTADOS E DISCUSSÃO}

Destacaram-se, pelo teste $\mathrm{F}$ diferenças significativas entre os genótipos a nível de 5\% de probabilidade para os caracte-

Tabela 2. Análise conjunta dos quadrados médios dos genótipos $(G)$, dos ambientes $(E)$, da interação genótipo $x$ ambiente $(G \times E)$ e os parâmetros genéticos de coeficiente de variação genética $(\mathrm{CVg} \%$ ), o índice b (razão entre $\mathrm{CVg} / \mathrm{CVe})$, herdabilidade $\left(\mathrm{hm}^{2} \%\right.$ ) em 12 caracteres de arroz de terras altas em Vitória de Santo Antão (PE) e Palmares (PE), 2006

\begin{tabular}{|c|c|c|c|c|c|c|c|}
\hline \multirow[b]{2}{*}{ Variáveis } & \multicolumn{3}{|c|}{ Quadrados médios } & \multicolumn{4}{|c|}{ Parâmetros genéticos } \\
\hline & G & $\mathbf{E}$ & $\overline{G \times E}$ & $\overline{C V g}(\%)$ & Índice b & $\begin{array}{c}\mathrm{hm}^{2}(\%) \\
\text { Palmares }\end{array}$ & $\begin{array}{c}\mathrm{hm}^{2}(\%) \\
\text { V.S.Antão }\end{array}$ \\
\hline $\begin{array}{l}\text { Altura de planta - } \\
\operatorname{AP}(m)\end{array}$ & $0,34^{*}$ & $0,29 *$ & $0,01^{*}$ & 14,7 & 3,3 & 98 & 97,0 \\
\hline $\begin{array}{l}\text { Ciclo de } \\
\text { florescimento - } \\
\text { CF (dias) }\end{array}$ & $288,10 *$ & $615,09 *$ & $51,64 *$ & 7,7 & 1,9 & 98 & 87,0 \\
\hline $\begin{array}{l}\text { Ciclo de } \\
\text { maturação - CM } \\
\text { (dias) }\end{array}$ & $206,51 *$ & $0,01 n s$ & $0,08 \mathrm{~ns}$ & 5,0 & 2,9 & 97 & 97,0 \\
\hline $\begin{array}{l}\text { Comprimento da } \\
\text { panícula - CP } \\
\text { (cm) }\end{array}$ & $18,70^{*}$ & $69,92 *$ & 3,73 ns & 5,7 & 0,9 & 71 & 83,0 \\
\hline $\begin{array}{l}\text { Perfilhamento } \\
\text { médio - PM }\end{array}$ & $1,63 *$ & $15,48^{*}$ & $0,38 \mathrm{~ns}$ & 16,9 & 0,8 & 77 & 74,0 \\
\hline $\begin{array}{l}\text { Peso de mil } \\
\text { grãos - PMG (g) }\end{array}$ & $41,81^{*}$ & $12,06^{*}$ & $2,91 \mathrm{~ns}$ & 8,8 & 1,6 & 93 & 88,0 \\
\hline $\begin{array}{l}\text { Produtividade - } \\
\text { PROD (kg/ha) }\end{array}$ & $1,26 \mathrm{~ns}$ & $30,52 *$ & $0,92 \mathrm{~ns}$ & 4,3 & 0,3 & 68 & 1,5 \\
\hline Renda - RE (g) & 9,81 ns & $3,80 *$ & $4,27 \mathrm{~ns}$ & 1,4 & 0,3 & 10 & 0,0 \\
\hline $\begin{array}{l}\text { Rendimento de } \\
\text { grãos - RG (g) }\end{array}$ & $164,69 *$ & $3,97 *$ & 8,69 ns & 8,6 & 1,1 & 75 & 86,0 \\
\hline $\begin{array}{l}\text { \% de espiguetas } \\
\text { estéreis por } \\
\text { planta - PEEP }\end{array}$ & 0,02 ns & $0,05^{*}$ & $0,01^{*}$ & 10,6 & 0,5 & 79 & 73,0 \\
\hline $\begin{array}{l}\% \text { de espiguetas } \\
\text { férteis por planta } \\
\text { - PEFP }\end{array}$ & $0,03 \mathrm{~ns}$ & $0,07 *$ & 0,02 ns & 3,1 & 0,3 & 79 & 73,0 \\
\hline
\end{tabular}

res AP, CF, CM, CP, PM, PMG e RG (Tabela 2); verifica-se também diferença significativa entre os ambientes para todos os caracteres analisados, exceto para $\mathrm{CM}$ e, em relação à interação genótipo $\mathrm{x}$ ambiente, os caracteres AP, CF e PEEP apresentaram diferenças significativas, sinal de que os genótipos avaliados se comportaram de forma diferenciada nos ambientes para as referidas

As estimativas de herdabilidade no experimento conduzido em Palmares variaram de 10 a 98\%. Para AP, CF, CM e, PMG, foram observados altos valores, entre 93 a $98 \%$ e, valores médios entre 65 a $79 \%$ para CP, PM, PEEP e PEFP (Tabela 2); constatou-se baixa herdabilidade (10\%) apenas para RE.

Em Vitória de Santo Antão verificou-se herdabilidade entre 0 a $97 \%$; foram constatadas altas herdabilidades, entre 83 a 97\%, para AP, CF, CM, CP, PMG e RG, e percentuais médios, entre 73 e 74\%, para PM, PEEP e PEFP (Tabela 2). Para os caracteres RE e PROD verificaram-se baixos valores 0 (zero) e $1,5 \%$, respectivamente. Baixo percentual de herdabilidade ocorre quando se tem baixa variância genética e elevada variância ambiental. Segundo Cruz (2005) quando a herdabilidade é baixa o valor fenotípico não é uma medida confiável do valor genotípico, pois a superioridade aparente de um indivíduo em relação a outro poderá não ser devida à causa genética; nesta situação, o processo seletivo poderá ser comprometido.

No presente trabalho, para a maioria dos caracteres estudados a herdabilidade foi entre alta e média, indicando que o fenótipo expressa o genótipo e, como se trata de genótipos fixados de uma espécie autógama, a maior quantidade da variabilidade é aditiva, ou seja, a herdabilidade é restrita $\left(\mathrm{h}_{\mathrm{r}}^{2}\right)$; portanto, para a maioria dos caracteres há possibilidade de obtenção de ganhos com seleção em programas de melhoramento genético da cultura do arroz.

Santos et al. (2001) avaliando a predição do potencial genético de populações segregantes de arroz de terras altas em Lavras e Patos de Minas, MG, descreveram percentuais de herdabilidade similares aos observados nesses experimentos para o carácter altura de planta, de 56,8 a $87,1 \%$, e ciclo de florescimento de 91,5 a $98,5 \%$, citando-os como percentuais médio e alto.

Em relação ao coeficiente de variação genética $(\mathrm{CVg})$ estimado para os dois locais (Tabela 2), foi confirmada reduzida variabilidade entre os genótipos para as caracteres ciclo de florescimento, ciclo de maturação, comprimento de panícula, peso de mil grãos, produtividade, renda, rendimento de grãos, percentual de espiguetas estéreis e percentual de espiguetas férteis, variando de 1,4 a 10,6\%. Santos et al. (2001) observaram $\mathrm{CVg}$ equivalente para os caracteres altura de plantas $(6,14)$ e ciclo de florescimento $(8,81)$, afirmando que esses valores são satisfatórios e favoráveis à seleção de genótipos superiores. Para os caracteres AP, CF, CM, PMG e RG, observou-se a razão entre $\mathrm{CVg} / \mathrm{CVe}$ ou índice b superiores a 1 (Tabela 2); referidos resultados são satisfatórios pois, segundo Vencovsky \& Barriga (1992), quando o índice b atinge valores superiores a 1, indica situação favorável ao ganho genético com a seleção e, em relação aos demais caracteres estudados, observou-se índice b inferior a 1. 
Os coeficientes de variação experimental mostraram, em sua maioria, boa precisão dos experimentos, com valores entre 1,69 e 21,18 (Tabela 2); notou-se CV baixo para AP $(4,39), \mathrm{CF}(3,97)$, CM $(1,69)$, CP (6,43), PMG $(5,51)$, RE $(5,02)$ e RG $(7,84)$ médio para as variáveis PROD $(16,1), \operatorname{PEEP}(19,07)$ e $\operatorname{PEFP}(11,01)$ e alto para PM $(21,18)$ conforme Gomes $(1987)$.

Em relação ao comportamento dos genótipos para os 12 caracteres avaliados constatou-se que, para o carácter altura de plantas (AP), os genótipos que apresentaram a maior menor média nos dois locais foram IAC 47 e PB 5, respectivamente, sendo que o IAC 47 não diferiu estatisticamente do Maravilha, em ambos os locais; houve alteração na ordem de classificação para os demais genótipos, considerando-se os dois ambientes (Tabela 3).

Tabela 3. Comparação entre médias obtidas para os caracteres altura de planta (AP), ciclo de florescimento (CF) e percentual de espiguetas estéreis por planta (PEEP) que mostraram interação genótipo $x$ ambiente significativa entre os genótipos, nos municípios de Palmares e de Vitória de Santo Antão

\begin{tabular}{|c|c|c|c|c|c|c|}
\hline \multirow{2}{*}{ Genótipos } & \multicolumn{3}{|c|}{ Palmares } & \multicolumn{3}{|c|}{ Vitória de Santo Antão } \\
\hline & $\mathrm{AP}(\mathrm{m})$ & CF(d) & PEEP* & $\mathrm{AP}(\mathrm{m})$ & CF(d) & $\begin{array}{l}\text { PEEP* } \\
\end{array}$ \\
\hline IAC 47 & $1,68 \mathrm{a}$ & $69 c$ & $0,31 \mathrm{~b}$ & $1,76 \mathrm{a}$ & $74 \mathrm{~b}$ & $0,43 a$ \\
\hline Bonança & $1,17 d$ & $52 \mathrm{e}$ & $0,36 b$ & $1,23 d$ & $68 \mathrm{~b}$ & $0,25 b$ \\
\hline Rio Parnaíba & $1,56 b$ & $70 \mathrm{~b}$ & $0,36 \mathrm{~b}$ & $1,62 \mathrm{a}$ & $74 \mathrm{~b}$ & $0,40 \mathrm{a}$ \\
\hline Maravilha & $1,63 \mathrm{a}$ & $68 c$ & $0,39 a$ & $1,71 \mathrm{a}$ & $76 \mathrm{~b}$ & $0,30 \mathrm{a}$ \\
\hline Caiapó & $1,31 \mathrm{c}$ & $74 \mathrm{~b}$ & $0,34 b$ & $1,56 \mathrm{~b}$ & $71 \mathrm{~b}$ & $0,31 \mathrm{a}$ \\
\hline BRA 1506 & $1,28 d$ & $69 c$ & $0,45 a$ & $1,36 \mathrm{c}$ & $71 b$ & $0,45 a$ \\
\hline BRA 1600 & $1,29 \mathrm{c}$ & $60 \mathrm{~d}$ & $0,40 a$ & $1,42 \mathrm{~b}$ & $68 \mathrm{~b}$ & $0,32 \mathrm{a}$ \\
\hline CNAs 9045 & $1,19 d$ & $61 \mathrm{~d}$ & $0,29 b$ & $1,37 \mathrm{c}$ & $68 \mathrm{~b}$ & $0,28 a$ \\
\hline CNA 9025 (sertanejo) & $1,27 d$ & $64 d$ & $0,45 a$ & $1,45 b$ & $72 b$ & $0,35 a$ \\
\hline BRSMG (curinga) & $1,21 d$ & $70 \mathrm{~b}$ & $0,42 a$ & $1,27 \mathrm{C}$ & $72 b$ & $0,25 \mathrm{~b}$ \\
\hline BRS (primavera) & $1,40 \mathrm{C}$ & $68 c$ & $0,39 a$ & $1,47 \mathrm{~b}$ & $69 \mathrm{~b}$ & $0,25 \mathrm{~b}$ \\
\hline PB 5 & $0,94 \mathrm{e}$ & $84 \mathrm{a}$ & $0,49 a$ & $1,05 \mathrm{e}$ & $85 a$ & $0,47 a$ \\
\hline
\end{tabular}

Médias seguidas da mesma letra da coluna não diferem estatisticamente a nível de 5\% de probabilidade, pelo teste de Tukey. $\mathrm{m}=$ metro, $\mathrm{d}=$ dias e $*$ valores transformados em arco seno

O genótipo Caiapó, que teve altura média de 1,31 e 1,56 m em Palmares e em Vitória de Santo Antão, respectivamente, também foi avaliado por Soares et al. (2003b), nos municípios de Lambari, Leopoldina e Piumhi, MG, tendo apresentado porte médio $(1,20 \mathrm{~m})$, citado como adequado para esta modalidade de cultivo.

A altura das plantas é uma característica altamente correlacionada com seu acamamento no final do ciclo da cultura. Nos dois experimentos conduzidos na Zona da Mata de Pernambuco, os genótipos IAC 47 e Maravilha, apresentaram as maiores notas para acamamento 7 e 5 , respectivamente (Tabela 4), e mostraram altura de planta superior aos demais nos dois ambientes, exceto em Vitória de Santo Antão, onde os mesmos não diferiram estatisticamente do Rio Parnaíba (Tabela 3 ).

O acamamento das plantas no final do ciclo, afeta a produtividade dos genótipos visto que plantas acamadas impossibilitam a colheita mecanizada; entretanto, com os resultados observados para esses caracteres, os genótipos Bonança,
Tabela 4, Comparação entre as médias, média geral e coeficiente de variação da análise conjunta com os 12 genótipos de arroz de terras altas, avaliados em Vitória de Santo Antão (PE) e em Palmares (PE), 2006

\begin{tabular}{|c|c|c|c|c|c|c|c|c|c|}
\hline Genótipos & ACP & $\begin{array}{l}\text { CM } \\
\text { (d) }\end{array}$ & $\begin{array}{c}\mathrm{CP} \\
(\mathrm{cm})\end{array}$ & PM & $\begin{array}{l}\text { PMG } \\
\text { (g) }\end{array}$ & $\begin{array}{c}\text { PROD } \\
\left(\mathrm{kg} \mathrm{ha}^{-1}\right)\end{array}$ & $\begin{array}{l}\mathrm{RE} \\
\mathrm{(g)}\end{array}$ & $\begin{array}{l}\text { RG } \\
\text { (g) }\end{array}$ & PEFP* \\
\hline C 47 & 7 & $101 \mathrm{bcd}$ & $24,12 \mathrm{ac}$ & $24,12 \mathrm{ac}$ & : 26,23abc & $4,077 \mathrm{a}$ & 56,58a 5 & $50,97 a b$ & b 1,20a \\
\hline onança & 1 & 97de & $22,60 b c$ & $22,60 \mathrm{bc}$ & $=21,77 d$ & 4,976a & 58,80 a 5 & $55,26 a b$ & b 1,27a \\
\hline $\begin{array}{l}0 \\
\text { rnaíba }\end{array}$ & 3 & $103 b$ & $24,38 a c$ & $24,38 \mathrm{ac}$ & : 29,14a & 4,823a & 56,50a 5 & 52,15 & $1,19 a$ \\
\hline aravilha & 5 & $101 \mathrm{bcd}$ & 22,6 & 22 & : $27,25 \mathrm{ab}$ & $4,514 a$ & $58,25 a 5$ & $51,72 a b$ & b 1,22a \\
\hline iapó & 3 & $103 b c$ & 22,7 & 22,7 & $3 b c$ & 5,0 & 58, & $55,87 a b$ & b 1,24a \\
\hline 506 & 1 & 99cde & 25,6 & 25,6 & $a b c$ & $=4,6$ & $56,10 a_{4}$ & $46,31 b c$ & c $1,12 a$ \\
\hline 1600 & 3 & $95 \mathrm{e}$ & $24,58 \mathrm{ac}$ & $24,58 a c$ & $23,30 \mathrm{~cd}$ & $4,153 a$ & 59,07 a 5 & $51,05 a b$ & b 1,21a \\
\hline & 1 & $6 e$ & $22,59 b c$ & $22,59 b c$ & $=2460 \mathrm{hrcd}$ & 4,805a & 59,81 & $56,14 a$ & a \\
\hline & 3 & 97de & $26,37 a$ & $26,37 a$ & $26,86 a b$ & $5,209 a$ & 57,7 & ,18 & , 17a \\
\hline & 1 & 99cde & $22,46 b$ & 2 & $8 b c$ & 5,017 & 58 & 72 & $1,23 a$ \\
\hline 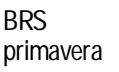 & 5 & 98de & 25,49ab & 25 & $02 \mathrm{~cd}$ & 4,19 & 57,8 & 50,8 & 28a \\
\hline B 5 & 1 & $115 a$ & $21,60 \mathrm{c}$ & $21,60 \mathrm{c}$ & $21,87 d$ & $5,015 a$ & $57,52 \mathrm{a}$ & $39,75 c$ & $1,09 a$ \\
\hline lédia & 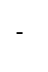 & 100 & 23,77 & 23,77 & 24,99 & 5,659 & 57,96 & 51,17 & 1,21 \\
\hline CV\% & - & 1,69 & 6,43 & 6,43 & 551 & 16,1 & 5,02 & 7,84 & 11,01 \\
\hline
\end{tabular}

Médias seguidas da mesma letra da coluna não diferem estatisticamente a nível de $5 \%$ de probabilidade, pelo teste de Tukey; ACP (acamamento da planta), CM (ciclo de maturação), CMP (comprimento médio de panícula), PM (perfilhamento médio), PMG (peso de mil grãos), PROD produtividade), RE (renda), RG (rendimento), PEFP (percentual de espiguetas férteis por panícula); * valores transformados em arco seno

BRA 1506, CNAs 9045 e BRSMG curinga e PB 5, foram os que apresentaram os melhores comportamentos.

Com relação ao ciclo de florescimento, o genótipo Bonança se destacou como mais precoce em Palmares (52 dias) enquanto em Vitória de Santo Antão seu ciclo foi igual à maioria dos genótipos, mas inferior apenas em relação ao PB 5, que foi o mais tardio nos dois locais (Tabela 3).

Em relação ao ciclo de maturação, observou-se média variando de 95 a 115 dias entre os genótipos, em que BRA 1600 apresentou o ciclo mais curto e não diferiu estatisticamente dos CNA 9045, CNAs 9025, BRS primavera, BRSMG curinga, BRA 1506 e do Bonança; o genótipo PB 5 apresentou CM mais tardio e diferiu estatisticamente dos demais (Tabela 4).

Alguns desses genótipos também foram avaliados quanto ao ciclo, em outras regiões do Brasil. Os genótipos Bonança e Caiapó apresentaram ciclo de florescimento de 91 e 97 dias, respectivamente, em Goiás (Moura Neto et al., 2002); já em experimentos realizados nos municípios de Lambari, Leopoldina e Piumhi, MG, Caiapó teve ciclo de florescimento de 100 dias (Soares et al., 2003a). O genótipo Primavera apresentou ciclo de 70 dias no Pará (Lopes \& Silveira Filho, 2002) e de 85 dias em Goiás (Moura Neto et al., 2002). O genótipo IAC 47 apresentou ciclo de 86 dias no Amapá (Atroch et al., 1999) e PB 5 teve ciclo de maturação de 113 dias no Piauí (Pereira et al., 2007). Os resultados do presente trabalho mostram variação no comportamento de alguns genótipos para ciclo de flo- 
Tabela 5. Médias dos índices pluviométricos ( $\mathrm{mm}$ ) no ano de 2006 e médias históricas dos meses de abril a agosto nos município de Palmares - Zona da Mata de Pernambuco e Vitória de Santo Antão

\begin{tabular}{|c|c|c|c|c|}
\hline \multirow[b]{2}{*}{ Meses } & \multicolumn{2}{|c|}{ Palmares } & \multicolumn{2}{|c|}{ Vitória de Santo Antão } \\
\hline & $\begin{array}{l}\text { Médias de } \\
2006\end{array}$ & $\begin{array}{c}\text { Médias } \\
\text { históricas }\end{array}$ & $\begin{array}{l}\text { Médias de } \\
2006\end{array}$ & $\begin{array}{c}\text { Médias } \\
\text { históricas }\end{array}$ \\
\hline Abril & 164,5 & 182 & 79,9 & 137 \\
\hline Maio & 245,4 & 238 & 124,7 & 157 \\
\hline Junho & 232,8 & 236 & 240,7 & 151 \\
\hline Julho & 172,6 & 209 & 99,9 & 151 \\
\hline Agosto & 80,7 & 130 & 72,0 & 72 \\
\hline
\end{tabular}

Fonte: ITEP (2006)

rescimento, nas diferenciadas condições climáticas em que foram avaliados; entretanto, com exceção do genótipo PB 5, com ciclo de florescimento de 84 dias e ciclo de maturação de 115 dias, os demais genótipos se comportaram de forma compatível com o cultivo de arroz de terras altas na Zona da Mata de Pernambuco, já que os índices pluviométricos médios históricos e os registrados em 2006 para os meses de abril a agosto de 2006 (Tabela 5); permitem completar o ciclo da cultura sem déficit hídrico.

O PB 5, por apresentar ciclo mais longo pode, eventualmente, ser exposto a períodos de escassez de chuva na fase de maturação dos grãos enquanto os demais apresentaram ciclos de florescimento adequado para o cultivo de arroz na Zona da Mata de Pernambuco.

O comprimento de panículas é uma característica correlacionada com a quantidade de espiguetas por panículas e com a produtividade. Neste trabalho, o genótipo CNA 9025 apresentou a maior média para o carácter $(26,37)$, não diferindo estatisticamente do IAC 47, Rio Parnaíba, Caiapó, BRA 1506, BRA 1600 nem da BRS primavera (Tabela 4). O genótipo PB 5 indicou a menor média para esta característica; contudo, não se verificou diferença estatística significativa em relação aos genótipos BRSMG curinga, CNAs 9045, BRA 1600, Caiapó, Maravilha, Rio Parnaíba, Bonança e IAC 47.

Em relação ao carácter perfilhamento médio por planta, costatou-se média geral de 2,32; sendo que o genótipo BRSMG Curinga apresentou a maior capacidade para emissão de perfilhos com 3,51; entretanto, não diferiu estatisticamente do IAC 47, Maravilha, Caiapó, BRA 1506 e PB 5 (Tabela 4). A boa capacidade de perfilhamento pode influenciar positivamente na produtividade, quando o maior número de perfilho resulta em maior número de panícula por planta.

Para o carácter PMG, a maior média foi observada para o genótipo Rio Parnaíba $(29,14$ g) não diferindo estatisticamente do IAC 47, Maravilha, BRA 1506 e CNAs 9045. A menor média foi notada para o genótipo Bonança $(21,77$ g), porém não diferiu estatisticamente dos genótipos BRA 1600, CNAs 9045, BRSMG curinga, BRS primavera e PB 5 (Tabela 4). No Brasil é notória a preferência do consumidor por grãos longos e finos, características que determinam menores pesos de mil grãos. Este carácter é correlacionado negativamente com o rendimento no beneficiamento, já que grãos longos e finos são mais propícios a quebrarem, mas neste trabalho tal correlação não foi observada, visto que CNAs 9045 , que tem grão longo fino, apresentou o maior rendimento $(56,14)$, em decorrência, provavelmente, de fatores ambientais.

Para o carácter produtividade observou-se média geral de $5.659 \mathrm{~kg} / \mathrm{ha}^{-1}$, não apresentando diferença estatisticamente significativa entre os genótipos. As maiores produtividades foram observadas para CNAs 9025, PB 5, Caiapó e BRSMG curinga, com 5.209, 5.015, 5.058 e $5.017 \mathrm{~kg} \mathrm{ha}^{-1}$, respectivamente (Tabela 4). Em relação à produtividade, todos os genótipos mostraram comportamentos compatíveis para o cultivo de arroz de terras altas na Zona da Mata de Pernambuco, haja vista que apresentaram médias superiores à produtividade nacional de arroz que, em 2005, foi de $3.865 \mathrm{~kg} \mathrm{ha}^{-1}$ (CONAB, 2007).

Em relação à produtividade, alguns dos genótipos avaliados nos dois experimentos na Zona da Mata de Pernambuco, também foram testados em outras regiões do Brasil e tiveram comportamento diferente. O genótipo Bonança apresentou produtividade de $3.785 \mathrm{~kg} \mathrm{ha}^{-1}$ e o Primavera $2.975 \mathrm{~kg} \mathrm{ha}^{-1} \mathrm{em}$ Capitão Poço e Paragominas, PA, respectivamente, (Lopes \& Silveira, 2002); esses mesmos genótipos foram avaliados por Moura Neto et al. (2002) em Goiás, sendo que Bonança indicou produtividade de 6.143 e Primavera de $6.362 \mathrm{~kg} \mathrm{ha}^{-1}$.

O genótipo Caiapó mostrou produtividade de $4.600 \mathrm{~kg} \mathrm{ha}^{-1}$ em avaliação realizada por Moura Neto et al. (2002) em Goiás, $3.501 \mathrm{~kg} \mathrm{ha}^{-1}$ nos municípios de Lambari, Leopoldina e Piumhi MG (Soares et al., 2003a) e $2.758 \mathrm{~kg} \mathrm{ha}^{-1}$ em Rondônia (Utimi et al., 2001); portanto, a produtividade observada para os genótipos Caiapó, Bonança e Primavera na Zona da Mata de Pernambuco, mostrou-se superior ou similar aos resultados observados em outras regiões.

Para o carácter renda, não houve diferença estatística significativa entre os genótipos e a média geral foi de 57,96 g. Os melhores desempenhos foram observados para CNAs 9045 $(59,81 \mathrm{~g})$, BRA $1600(59,07 \mathrm{~g})$ e Bonança $(58,80 \mathrm{~g})$. Em relação à variável rendimento, diferenças estatisticamente significativas foram notadas entre os genótipo, sendo que CNAs 9045 apresentou a maior média $(56,14 \mathrm{~g})$ porém não deferiu do IAC 47, Bonança, Rio Parnaíba, Maravilha, Caiapó, BRA 1600, CNAs 9045, CNAs 9025, BRSMG curinga e BRS primavera. O genótipo PB 5 apresentou a menor média $(39,75 \mathrm{~g})$ que diferiu estatisticamente dos demais genótipos, exceto em relação ao BRA 1506 (Tabela 4).

A legislação brasileira prevê rendimento de benefício de 40 a $68 \%$ para grãos inteiros (Vieira \& Carvalho (1999); portanto, os percentuais de rendimento observados para os genótipos, com exceção de PB 5, na Zona da Mata de Pernambuco, superaram o percentual mínimo.

Para o caráter porcentagem de espiguetas estéreis por panícula, IAC 47, Bonança, Rio Parnaíba, Caiapó e CNAs 9045 tiveram menores médias em Palmares e diferiram estatisticamente dos demais genótipos. Em Vitória de Santo Antão, Bonança, BRSMG (curinga) e BRS (primavera) tiveram menores médias, as quais diferiram estatisticamente dos demais genótipos. Embora não se tenha observado, no trabalho, este caráter é correlacionado com a produtividade dos genótipos, 
pois altos percentuais podem influenciar negativamente no número de grãos por panícula (Tabela 3).

Em relação à porcentagem de espiguetas férteis por panícula, as diferenças entre os genótipos não foram estatisticamente significativas e a maior média foi constatada para o genótipo CNAs 9045 (1,29 ) enquanto PB 5 apresentou a maior média de espiguetas férteis por panícula $(1,09)$. Normalmente, o maior percentual de espiguetas férteis por panícula proporciona maior produtividade aos genótipos embora isto não tenha sido observado para os genótipos estudados neste trabalho (Tabela 4).

\section{CONCLUSÕES}

1. Os genótipos Bonança, BRA 1506, CNAs 9045 e BRSMG curinga, apresentaram os melhores comportamentos em terras altas na Zona da Mata de Pernambuco em relação aos caracteres altura da planta, acamamento, ciclo de florescimento, ciclo de maturação, perfilhamento médio e rendimento de grãos.

2. Nas condições da Zona da Mata de Pernambuco, os genótipos Bonança, BRA 1506, CNAs 9045 e BRSMG curinga apresentaram comportamento compatível com o cultivo em terras altas, no período de abril a julho, e poderão ser recomendados para a referida região.

\section{AGRADECIMENTOS}

Ao pesquisador José Almeida Pereira, do Centro de Pesquisa Agropecuária Meio Norte, EMBRAPA, por disponibilizar sementes para a realização dos experimentos.

Às pesquisadoras $\mathrm{Sr}^{\mathrm{a}}$. Vânia Trindade Barretto Canuto e Graciete Helena da Silva, do Laboratório de Sementes da Empresa Pernambucana de Pesquisa Agropecuária (IPA) por concederem a máquina para beneficiamento dos grãos.

À Escola Agrícola de Palmares e à Escola Agrotécnica de Vitória de Santo Antão, por cederem a área para implantação dos experimentos.

\section{LITERATURA CITADA}

Atroch, A. L.; Morais, O. P.; Rangel, P. H. N.; Castro, E. M. Progresso do melhoramento genético do arroz de sequeiro no Estado do Amapá. Pesquisa Agropecuária Brasileira, v.34, p.1623-1632, 1999.

Azzini, L. E.; Bastos, C. R.; Villela, O. V.; Gallo, P. B.; Soave; J. Castro; L. H. S. M.; Tisseli Filho, O. O. Melhoramento do arroz: Comportamento de cultivares e linhagens de arroz irrigado no Estado de São Paulo em 1990/91 e 1991/92. Bragantia, v.4, p.287-296, 1995.

Breseghello, F.; Stone, L. F. Tecnologia para o arroz de terras altas. Santo Antônio de Goiás: Embrapa Arroz e Feijão, 1998. 161p.

CONAB-Companhia Nacional de Abastecimento. http:// www.conab.gov.br/conabweb/index.php?PAG=1 >: 20 Ago. 2007.
Crusciol, C. A. C.; Mauad, M.; Alvarez, R. C. F.; Lima, E. V.; Tiritan, C. S. Doses de fósforo e crescimento radicular de cultivares de arroz de terras altas. Bragantia, v.64, p.643 -650, 2005.

Cruz, C. D. Programa Genes: Aplicativo Computacional. Viçosa: UFV, 1997. 442p.

Cruz, C. D. Princípios de genética quantitativa. Viçosa: UFV, 2005. 394p.

Cruz, C. D.; Regazzi, A. J.; Carneiro, P. C. S. Modelos biométricos aplicados ao melhoramento genético. 3.ed. Viçosa: UFV. 2004. 480p.

EMBRAPA - Empresa Brasileira de Pesquisa Agropecuária. Manual de métodos de pesquisa em arroz. Goiânia: Centro Nacional de Pesquisa de Arroz e Feijão, 1977. 106p.

Falconer, D. S. Introdução à genética quantitativa. Viçosa: UFV, 1987.279p.

Ferreira, C. M.; Pinheiro, B. S.; Sousa, I. S. F.; Morais, O. P. Qualidade do arroz no Brasil: Padronização. Santo Antonio de Goiás: Embrapa Arroz e Feijão, 2005. 61p.

Gomes, F. P. Estatística moderna na pesquisa agropecuária. Piracicaba: Associação Brasileira para Pesquisa Agropecuária da Potassa e Fosfato, 1987. 160p.

Guimarães, E. P.; Sant' ana, E. P. Sistemas de cultivo. In: Vieira, N. R. A.; Santos, A. B.; Sant'ana, E. P. A cultura do arroz no Brasil. Santo Antonio de Goiás: Embrapa Arroz e Feijão, 1999. p.17-35.

IBGE - Instituto brasileiro de geografia estatística. <http: www.sidra.ibge.gov.br >: 28 Jul. 2006.

ITEP - Instituto Tecnológico de Pernambuco 2006 (Dados de relatórios internos)

Lopes, A. M.; Silveira Filho, A.; Bonança: Cultivar de arroz de sequeiro recomendada para a região nordeste do Estado do Pará. Belém do Pará, Ministério da Agricultura, Pecuária e Abastecimento, 2002. 4p. (Comunicado Técnico, 72)

Ministério da Agricultura do Brasil. Regras para análise de sementes. Brasília: SNDA/DNDV/CLAV, 1992. 365p.

Moura Neto, F. P.; Soares, A. A.; Aidar, H. Desempenho de cultivares de arroz de terras altas sob plantio direto e convencional. Ciência e Agrotecnologia, v.26, p.904 -910, 2002.

Muralidharan, K.; Prasad, G. S. V.; Rao, C. S. Yield performance of rice genotypes in internacional multi-enviroment trials during 1976-1997. Current Science, v.83, p.610-619, 2002.

Pereira, J. A.; Bassinello, P. Z.; Fonseca, J. R.; Ribeiro, V. Q. Revista Caatinga, v.20, p.43-48, 2007.

Rangel, P. H. N. Desenvolvimento de cultivares de arroz irrigado para o Estado do Tocantins. Lavoura Arrozeira, v.48, n.424, p.11-13, 1995.

Santos, P. G.; Soares, A. A.; Ramalho, M. A. P. Predição do potencial genético de populações segregantes de arroz de terras altas. Pesquisa Agropecuária Brasileira, v.36, p.659-670, 2001.

Soares, A. A.; Cornélio, V. M. de O.; Reis, M.de S.; Soares, P. C.; Santos, P. G.; Sousa, M. A. Desempenho de linhagens de arroz de terras altas quanto à produtividade de grãos e outras características em Minas Gerais. Revista Ceres, v.50, p.509-525, 2003a.

Soares, A. A.; Reis, M. de S.; Soares, P. C; Cornélio, V. M. de O.; Santos, P. G.; Desempenho e seleção de cultivares e linhagens de arrroz de sequeiro cultivados em várzea úmida. Revista Ceres, v.50, p.527-541, $2003 \mathrm{~b}$. 
Utimi, M. M.; Godinho, V. de P. C.; Prado, E. E. do; Ramalho, A. R.; Castro, E. da M. de.; Breseghello. Avaliação de genótipos de arroz (Oryza sativa L.) no Estado de Rondônia - safra 1999/2000. Brasília, 2001. p.1-15. Comunicado Técnico, 189. Vencovsky, R.; Barriga, P. Genética biométrica no fitomelhoramento. Ribeirão Preto: Sociedade Brasileira de Genética, 1992. 496p.
Vieira, N. R. A; Carvalho, J. L.V. Qualidade tecnológica. In: Veira, N. R. A.; Santos, A. B.; Sant'ana, E. P. A cultura do arroz no Brasil. Santo Antonio de Goiás: Embrapa Arroz e Feijão, 1999. p.582-598.

Villar, P. M. Del; Ferreira, C. M. Dinâmica territoriais do arroz de terras altas na região Centro-Oeste do Brasil. Cadernos de Ciência e Tecnologia, v.22, p.97-107, 2005. 